\title{
Organizational Culture and Emergency Response Actions: How Japanese Companies Behave?
}

\author{
Asako Takada \\ E-Mail: morning-star@nifty.com \\ Takachiho University \\ Eri Yokota \\ E-Mail: yokota@fbc.keio.ac.jp \\ Keio University
}

\begin{abstract}
Are Japanese companies insensitive for the crisis? From our survey, it is clear that the strong top down style management is not supported but bottom up style of management is supported. Also, in connection with the organization culture, it can be surmised that companies with a cheerful family-type culture are better able to effect a coordinated response to an emergency. In this type of culture, information tends to be passed on freely, and rather than having employees carry out response actions based on orders and directives conscious of the intentions of the top management.
\end{abstract}

Keywords: Word-of-Mouth Communication, Negative Message, Perceived Risk, Instrumental Message, Affective Message, Reading Motive

\section{INTROUDUCTION}

Crisis management is not a special but an indispensable skill for management. For companies to survive, the most critical issue for management is to foresee and respond to irregular occurrences, and resume their operations as quickly as possible.

In this paper, we will focus on actions during an emergency and examine how Japanese companies respond to an emergency, and what kinds of organizations are best able to confront and surmount emergencies. 


\section{AIMS OF THIS PAPER}

This paper was prepared as a preliminary position for verifying what kinds of organizations are best able to respond to emergencies. This paper has two aims. The first is to clarify the current state of thinking in Japanese companies about their emergency response and verify the accepted view on this. The concern about emergency response among Japanese companies is said to have deepened following the multiple terrorist attacks in the U.S., however, reality is that there is no clear indication of what they view as an emergency, and how they would respond to any emergency. Traditionally, the mainstream thinking among Japanese companies is that "response to an emergency should be by a strong top-down organization," (Sassa, 1979). This is the view that decision-making in response to an emergency will be centralized with all information concentrated at the top management. This paper will examine whether this concept is still effective in today's world.

The second aim is to shed light on the connection between crisis management currently undertaken by Japanese companies and organizational culture. The issue of how to respond to an emergency is related to the sense of values of the organization, so in this sense, looking at the connection between organizational culture and the emergency response system should help us to consider emergency response from a new perspective.

Then, on this basis, the paper will examine the kind of organizational culture that ultimately should be developed for building an organization that is strong in an emergency.

\section{CRISIS MANAGEMENT RESEARCH: CONVENTIONAL VIEWS ON EMERGENCY RESPONSE}

Research into conventional crisis management has three broad characteristics (Takada, 2003). The first is that the basis of the response is the "return to the normal state", and "actions for returning to the previous state" is the mainstream view (Bohn 2000; Mitroff 1996: Mitroff \& Pearson, 1993). Therefore, one critical aspect for response has been to produce a response manual in preparation for risk, and take action in accordance with the manual when such an incident occurs.

Second, a key factor in a response is that the top management is required to display strong leadership (Ohizumi,1996; Myers, 1993). In most cases, the importance of a centralized response has been stressed through the use of military and war metaphors 
regarding the necessary actions by an organization in response to an emergency. Tiered organizations, which have long been the predominant structure, have been designed to concentrate authority and information at the top, and the scope of the responsibility of each tier is clearly defined. Considering a typical example of this tiered organization is the military, it has been quite reasonable to concentrate authority and emphasize the importance of leadership at the top.

The third is "the crisis response organization" has been structured as a top-down tiered organization where the top management comprising the senior managers form the "decision making center", and all information and decision making authority are concentrated there, while the local organizations are the "doers" that obediently carry out the directives and orders from the top (Augustine,1995). According to these traditional crisis management researches, the optimum method for companies facing an emergency is to prepare a manual and execute strong top-down leadership.

\section{REALITY OF COMPANY CRISIS MANAGEMENT: QUESTIONNAIRE RESULTS}

We conducted a questionnaire survey on the crisis management structure and organization of companies listed in the Tokyo Stock Exchange to determine whether actual crisis management in Japanese companies conforms to rules judged to be suitable by previous crisis management research (Note 1). The survey ran from the end of August to the end of September 2003, and questionnaires were mailed to the officers responsible for management planning. Questionnaires were sent to 2,132 companies, and 153 companies responded for a response rate of $7.17 \%$. Table 1 shows a breakdown of responding companies by industry type.

Table 1 Industries of Responding Companies

\begin{tabular}{|c|c|}
\hline Industries & percentage \\
\hline Construction & $7 \%$ \\
\hline Textile-related & $1 \%$ \\
\hline Petroleum-related & $9 \%$ \\
\hline Steel and non-ferrous metals-related & $5 \%$ \\
\hline Machinery and electrical appliance-related & $12 \%$ \\
\hline Other manufacturing & $25 \%$ \\
\hline Wholesale / retail & $17 \%$ \\
\hline Food & $2 \%$ \\
\hline Finance and real estate & $7 \%$ \\
\hline
\end{tabular}


Table 1 Industries of Responding Companies (Continued)

\begin{tabular}{lc}
\hline \multicolumn{1}{c}{ Industries } & percentage \\
Transport and communication & $2 \%$ \\
Information-related, advertising, consulting & $7 \%$ \\
Services & $5 \%$ \\
Others & $1 \%$ \\
\hline
\end{tabular}

\section{Emergencies envisaged by Japanese companies}

To clarify what Japanese companies envisage as an "emergency", we asked the companies to select three emergency occurrences they are most cautious about. From this, we were able to divide what they envisage as emergencies into two broad classifications: product-related emergencies, such as claims against the company's products; and emergency occurrences that are beyond the control of the company (Table 2). Of the 145 companies that provided effective responses, roughly half considered product defects (72 companies) and claims against their products (70) to be the major emergency occurrence. These were followed by natural disasters (62), system failure (57), and involuntary violation of the law (22).

The companies tended not see occurrences that are currently of common concern to the international community, such as hostile takeovers ( 7 companies), terrorist attacks (5), and defamation over the Internet (3) as emergencies that will occur to them.

Conversely, there was high concern about incidences that are highly likely to occur because of defects in their own products, and we could see that this is where these companies' focus is when considering responses to emergencies.

Table 2 Types of envisaged emergencies

\begin{tabular}{lcc}
\hline variables & $\begin{array}{c}\text { No. of } \\
\text { companies }\end{array}$ & $\begin{array}{c}\text { percentage to the } \\
\text { effective responses }\end{array}$ \\
Product defects & 72 & $49.66 \%$ \\
Claim against products & 70 & $48.28 \%$ \\
Natural disasters & 62 & $42.76 \%$ \\
System failure & 57 & $39.31 \%$ \\
Scandal involving employees & 42 & $28.97 \%$ \\
Industrial accident & 24 & $16.55 \%$ \\
Involuntary violation of the law & 22 & $15.17 \%$ \\
\hline
\end{tabular}


Table 2 Types of envisaged emergencies (Continued)

\begin{tabular}{lcc}
\hline variables & $\begin{array}{c}\text { No. of } \\
\text { companies }\end{array}$ & $\begin{array}{c}\text { percentage to the } \\
\text { effective responses }\end{array}$ \\
$\begin{array}{l}\text { Accident causing injury or death } \\
\text { within the company }\end{array}$ & 12 & $8.28 \%$ \\
$\begin{array}{l}\text { Political instability } \\
\text { Extortion/defamation of the }\end{array}$ & 8 & $7.59 \%$ \\
company & 8 & $5.52 \%$ \\
Accident causing injury or death & 7 & $5.52 \%$ \\
Hostile takeover & 6 & $4.83 \%$ \\
Spread of infectious diseases & 5 & $4.14 \%$ \\
Terrorist attack & 3 & $3.45 \%$ \\
Defamation over internet & 3 & $2.07 \%$ \\
Product tampering/ poisoning & 3 & $2.07 \%$ \\
Others & & $2.07 \%$ \\
\hline
\end{tabular}

\section{Methods of responding to emergencies}

We then asked the companies specifically how they would respond to an emergency. Of the 153 companies that gave an effective response, 102 companies, or $66 \%$, answered that they have a crisis management manual. The crisis management manuals generally give specific directions on the various actions that employees should take when disruption occurs because of an emergency to return the situation back to normal. It can be said that the manuals are aimed at facilitating a "return to the normal state" put forward by conventional crisis management research. So in this sense, $66 \%$ of companies view the aim to "return to the normal state" as the basis for their response actions during an emergency.

Moreover, 82 companies answered that they would respond to an emergency by establishing a crisis management committee or similar organization. Of these, 55 companies indicated that the committee would be headed by the company president, 10 companies indicated it would be the managing director, 12 companies indicated the executive director, and 7 the vice-president, so in almost all cases the committee would be chaired by an executive level company official. As for committee membership, 51 companies indicated 5-10, followed by 18 companies with 11-20. The highest number of 
companies (69) said that committee members would be chosen from among officials down to divisional director level.

On the other hand, 22 companies responded that they have neither a crisis management manual nor a crisis management committee. In other words, $14.3 \%$ of companies indicated that they do not have a manual to respond to emergencies, and that there is no special organizational response in an emergency so that the company can return to the normal state.

\section{Communication tools for responding to emergencies}

We asked companies to indicate how suitable the different kinds of communication tools are within the organization during an emergency on a seven-point scale. The most important communication tool was "verbal" communication with 5.33, followed by email with 5.27, while the least important was the electronic bulletin board with 4.30 .

\section{Emergency response policies in Japanese companies: Awareness and verification of} strong leadership displayed by top management

Table 3 shows the selection results of the three items considered to be the most important in an emergency.

Table 3 Items considered to be most important in an emergency

\begin{tabular}{lcc}
\hline variables & $\begin{array}{c}\text { Number of } \\
\text { companies }\end{array}$ & $\begin{array}{c}\text { Percentage of } \\
\text { the effective } \\
\text { responses }\end{array}$ \\
Passage of information within the organization & 84 & $57.5 \%$ \\
Clear chain of command and control & 80 & $54.8 \%$ \\
Leadership by top management & 79 & $54.1 \%$ \\
Achievement by the company of its social mission & 54 & $37.0 \%$ \\
Gather information at the top & 33 & $22.6 \%$ \\
Keep society informed of the situation & 27 & $18.5 \%$ \\
Saving life & 26 & $17.8 \%$ \\
Workplace commitment & 21 & $14.4 \%$ \\
Measures for the mass media & 12 & $8.2 \%$ \\
Completion of a response manual & 11 & $7.5 \%$ \\
\hline
\end{tabular}


Table 3 Items considered to be most important in an emergency (Continued)

variables

All decision making by top management and implementation at the workplace

Decision making at the workplace

Low cost

others
Number of companies

Percentage of the effective responses

From the table, we can see that the following three aspects were rated very highly timely passage of information within the organization (84 companies / 57.5\%), clear chain of command / control ( $80 / 54.8 \%$ ), and leadership by top management (79 / $54.1 \%$ ). Other aspects considered important by companies at this stage were achievement by the company of its social mission (54 companies / 37\%), gather information at the top (33 / 22.6\%), and keep society informed of the situation ( $27 / 18.5 \%)$.

On the other hand, what is thought about a strong top-down response, which has been considered the most important aspect in conventional crisis management research? Cross-analysis between "leadership by top management" and other items revealed a connection with the two items of "workplace commitment" and "clear chain of command and control" (see Table 4). Furthermore, cross-analysis between "all decision making by top management and implementation at the workplace" and the other items showed a connection between "gather information at the top" and "saving life", while cross analysis with "gather information at the top" showed a possible connection among "passage of information within the organization", "clear chain of command and control", and "all decision making by top management and implementation at the workplace".

Next, regarding cross-analysis of the three main elements (Table 4), null hypothesis, which states that there is no connection at a $10 \%$ significance probability in Fisher's direct method was rejected in the connection between "passage of information within the organization" and "clear chain of command and control" and the connection between "leadership by top management" and "clear chain of command and control". From this we can see that while companies are aware that a clear chain of command and control is critical at the time of an emergency, they do not necessarily see this in relation to leadership by top management. 
The results of the above can lead us to conclude that details specifying the "importance of top management" may in fact be quite divergent from those indicated by previous crisis management research. In previous research, a strong top-down type of response in which authority is concentrated at the top has tended to be considered the main stream of the crisis management. Of course, we can see that there are also companies that consider a response to emergencies by the conventional top-down tiered organization in which all authority is concentrated in the top management to be acceptable. On the other hand, while leadership by top management is considered necessary, we can see this does not necessarily mean that information is concentrated at the top and top management responds to the emergency directly in the role of decisionmaker. As shown in 3-2 above, the fact that almost half of the surveyed companies answered that they would not respond to an emergency through a crisis management committee or similar centralized organization also indicates this trend.

\section{Table 4 Cross-analysis of three elements}

Table 4.1 Result of cross analysis between "leadership by top management" and other items

Fisher's direct coefficient

Workplace commitment

$0.017^{*}$

Passage of information within the organization

0.179

Gather information at the top

0.165

Clear chain of command and control

$0.019 *$

Saving life

Achievement by the company of its social mission

0.304

Decision making at the workplace

Measures for the mass media

Keep society informed of the situation

All decision making by top management and implementation at the workplace

0.302

Completion of a response manual

0.755

Low cost

1.000

Note: Fisher's direct coefficient (accurate significance probability, both sides) $* \mathrm{p}<0.1$ 
Table 4.2 Results of cross-analysis between "all decision making by top management and implementation at the workplace" and the other items

\begin{tabular}{lc} 
& Fisher's direct coefficient \\
Leadership by top management & 0.302 \\
Workplace commitment & 1.000 \\
Passage of information within the organization & 0.489 \\
Gather information at the top & $0.028^{*}$ \\
Clear chain of command and control & 0.732 \\
Saving life & $0.054^{*}$ \\
Achievement by the company of its social mission & 0.485 \\
Decision making at the workplace & 1.000 \\
Measures for the mass media & 0.548 \\
Keep society informed of the situation & 1.000 \\
Completion of a response manual & 0.516 \\
Low cost & 1.000 \\
\hline
\end{tabular}

Fisher's direct coefficient (accurate significance probability, both sides)

$\mathrm{P}<0.1$

It can be inferred that while leadership must be displayed by top management in the sense of setting the direction of the organization when an emergency occurs and in the response to it, rather than spearheading the response, once the direction of the organization has been clearly set, top management should provide the necessary support for response at the lower operational levels. Top management plays a decision-making role in the aspect of setting the direction the organization should take, after which the workplace or lower operational levels take the central role. If, though, top management takes the centralized leadership role as put forward by conventional crisis management research, workplace commitment becomes more difficult to emphasize, or can tend to decline.

From management trends, what is required from the company organization these days is "delegation of decision-making authority to the workplace level" rather than "concentration of decision-making authority at the top". That is, there are no arguments that rather than all decision-making being concentrated at the top, it is essential that individuals at the workplace should be able to act with greater independence. 
Table 4.3 Results of cross-analysis between "Gather information at the top" and the other items

\begin{tabular}{lc}
\hline & Fisher's direct coefficient \\
\hline Leadership by top management & 0.165 \\
Workplace commitment & 1.000 \\
Passage of information within the organization & $0.009 *$ \\
Clear chain of command and control & $0.006^{*}$ \\
Saving life & 0.607 \\
Achievement by the company of its social mission & 0.417 \\
Decision making at the workplace & 0.350 \\
Measures for the mass media & 1.000 \\
Keep society informed of the situation & 0.819 \\
All decision making by top management and implementation at the workplace & $0.028^{*}$ \\
Completion of a response manual & 1.000 \\
Low cost & 1.000 \\
\hline
\end{tabular}

Fisher's direct coefficient (accurate significance probability, both sides)

$\mathrm{P}<0.1$

To date, the top-down approach has been understood as the standard for emergency response, but in business it has been pointed out that top management puts forward organizational policy and direction, while the workplace level carries out independent team activities within the framework of response standards received by way of valuesbased policies set by top management (Takada, 2004), and in fact there are growing moves within companies to review emergency response standards.

\section{THREE TYPES OF ORGANIZATIONAL CULTURE AND EMERGENCY RESPONSE}

We ascertained that the overall trend among Japanese companies in their response to emergencies is not necessarily the strong leadership by top management highlighted in the past, so next we examine the relationship between emergency response actions and organizational culture. It can easily be inferred that actions taken in response to an 
emergency are closely connected to the values of the organization. We therefore prepared 50 questions on organizational culture, and through factor analysis, we sought to extract the factors of organizational culture. For the survey items on organizational culture, we used the items in the organizational culture scale questionnaire prepared by Masahide Sekimoto et al. (2001). The survey revealed distinctive characteristics between the three organizational culture factors extracted and company emergency response systems.

\section{Three factors of organizational culture}

Although we did not extract any significantly major factors through rotation of the BARIMAX method without the major factor method and Kaiser normalization, three factors had a characteristic value after rotation of 2.5 or higher (cumulative load of $38.61 \%)$.

In each factor, the following are question elements with a correlation of at least 0.6. A strong negative correlation was seen in the first factor in "warm human relationship between superiors and subordinates", "can freely display individuality" and "can speak freely"; in the second factor in "do not disagree with those in authority", "do not change conventional methods", "responsibilities when a problem arises are not clearly set out" and "greater priority is given to one's own section or work than to the company"; and in the third factor in "discussion is important in planning", "act with the utmost caution" and "timely decision-making".

From result of above, we named the first factor "cheerful family-type organizational factor", the second "suckerfish-type organizational factor", and the third "caution-type organizational factor".

\section{Three factors and emergencies}

Next we examined the relationship between how emergencies are perceived and the organizational culture (Table 5) and the connection between the method of responding to an emergency and the organizational culture (Table 6) by determining the difference in the average values of the organizational culture factors between companies that selected the items and those that did not. Before this, we first tested the equality of variance of each question item, then divided the results into cases where equality of variance is assumed, and where it is not assumed. 
Table 5 Organizational culture tendencies and types of emergencies (examination of the difference in average values of organizational culture factors between companies that selected each item and those that did not)

\begin{tabular}{|l|c|l|l|}
\hline & $\begin{array}{c}\text { Cheerful family- } \\
\text { type }\end{array}$ & Suckerfish-type & Caution-type \\
\hline Natural disasters & & & \\
\hline Product defects & & & \\
\hline Hostile takeover & & & \\
\hline Spread of infectious diseases & & & \\
\hline Sudden death of executives & & & \\
\hline Abduction / murder of company & & & \\
\hline employees & & & \\
\hline Claims against products & & & \\
\hline Extortion / defamation of the company & & & \\
\hline System failure & & & \\
\hline Accident causing injury or death & & & \\
\hline outside the company & & & \\
\hline Scandal involving employees & & & \\
\hline Defamation over the Internet & & & \\
\hline Terrorist attack / Political instability & & & \\
\hline Product tampering / poisoning & & & \\
\hline Industrial accident & & & \\
\hline Insolvency of a major client & & & \\
\hline Others & & & \\
\hline Significant difference of $5 \%$ level & & & \\
\hline
\end{tabular}

$* *$ Significant difference of $5 \%$ level

* Significant difference of $10 \%$ level 
Table 6 Connection between emergency response actions and organizational culture factors (examination of the difference in average values of organizational culture factors between companies that selected each item and those that did not)

\begin{tabular}{|l|c|c|c|}
\hline & $\begin{array}{c}\text { Cheerful } \\
\text { family type }\end{array}$ & $\begin{array}{c}\text { Suckerfish- } \\
\text { type }\end{array}$ & $\begin{array}{c}\text { Caution } \\
\text {-type }\end{array}$ \\
\hline Leadership by top management & & & \\
\hline Workplace commitment & & & \\
\hline Passage of information within the organization & & & \\
\hline Gather information at the top & $* *$ & & \\
\hline Clear chain of command and control & & & \\
\hline Saving life & & & \\
\hline Achievement by the company of its social mission & & & \\
\hline Decision making at the workplace & & & \\
\hline Measures for the mass media & & & \\
\hline Keep society informed of the situation & & & \\
\hline Completion of a response manual & & & \\
\hline Low cost & & & \\
\hline
\end{tabular}

** Significant difference of $5 \%$ level

* Significant difference of $10 \%$ level

\section{Cheerful family-type factor}

Characteristics of the cheerful family-type factor are that the individuality of each employee in the company is respected, there is a warm human relationship, and employees are able to speak freely.

Considering the response to an emergency, while companies that envisage system failure and product tampering / poisoning as "emergencies" were at the $10 \%$ level, the "cheerful family-type factor" is high. A significant difference was seen in the emergency response action items of "saving life" and "clear chain of command and control". Of 
these, in companies which responded that a clear chain of command and control is important, the average value for the cheerful family-type factor was negative, whereas the average value was positive in companies which did not answer that it is important (0.1267 / 0.1638: average values of companies that selected the item and of those that did not; hereinafter the same).

It is assumed that company organizations themselves are very conscious of being a part of society, and that they view each employee as an asset. So it is thought that with their close connection with the community, they are inclined to seek to fulfill their social responsibility as companies and actively release information during an emergency.

\section{Suckerfish-type factor}

The suckerfish-type organizational culture lays great store on precedent, and tends not to actively assimilate new ways. Great importance is placed on what those in authority have to say, so responsibility of the individual tends to be ambiguous. This is a suckerfish-like character in which decisions are made on the basis of the leanings of the powerbrokers in the organization.

To the question of what are perceived emergencies, the average value for this factor in companies that selected the system failure item was negative (average value -0.3511 / 0.2227). Although at the $10 \%$ level, the average value for this factor was high for companies that envisaged terrorist attacks $(0.2043 /-0.008)$. Mass media response is also an organizational culture factor of companies that emphasize actions in response to an emergency $(0.5080 /-0.0270)$. Conscious of how they are perceived from the outside, these companies view their reputation as critical, and act accordingly, and in this sense, they are thought to have a strong concern about incidences they have no means of preventing, such as terrorist attacks.

However, there is no correlation with any of the other emergency response items, and there is minimal pattern of emphasizing anything in particular regarding the emergency response. It is surmised that an organizational culture that tends to blindly go along with the words of the powerbrokers perhaps does not prefer fixed views on emergency response, or, in other words, perhaps prefers to respond in accordance with the situation.

\section{Caution-type factor}

The caution-type is an organizational culture factor that requires the selection of safe 
and solid methods under any circumstances, and is timid regarding failure. The average value for this factor was high among companies that chose industrial accidents $(0.3459$ / $0.0483)$, and insolvency of a major client $(0.3865 /-0.0709)$ for the question of their perceived emergencies. Here we can see that they envisage accidents or disasters that will directly impact on their business. However, in none of the major emergency response action items was this cultural factor particularly strong.

The fact that nothing is especially emphasized in emergency response can be considered to imply that these companies tend stress maintenance of steadiness and regularity in normal company activities and in the process, deal with emergencies separately as they arise, rather than envisage various specific kinds of emergencies and organizationally prepare for them.

\section{Three organizational culture factors and emergency response}

The following can be considered regarding the three organizational culture factors and emergency responses by companies.

Companies with a cheerful family-type organizational culture factor tend to place greater emphasis on human being rather than cost and seek to achieve their social mission through workplace commitment in their response to an emergency compared to companies with the other two organizational culture factors. Companies with this factor tend to be passive in their response to emergencies with a clear chain of command and control; that is, with a top-down chain of command. In other words, they tend to believe that it is better for the workplace level to take various actions in response to an emergency.

Things happen at a much faster rate during an emergency than during normal times. Making the various rapid and timely decisions essential in an emergency is extremely difficult unless employees are fully aware of what needs to be done before the emergency occurs. It is necessary for workers to undertake their respective response actions with a clear concept that forms the foundations of "what they must do as a company" in response to various occurrences.

That is, companies with a cheerful family-type organizational culture seem to have a strong tendency for the top management and workplace to have no major differences from normal times and share common views on responses. This should be noted as a new way of emergency response not seen in previous crisis management research.

On the other hand, companies with a strong suckerfish-type factor do not have a 
particularly clear idea about emergency responses. They do not have the inclination toward action based on workers' commitment at the workplace seen in companies with a cheerful family-type factor. The fact that this organizational culture factor is strong in a company means that the company tends to check with those in authority before acting, and provided the company is led well, the response may actually turn the disaster into the company's advantage, but equally, if the company is not, then the company as a whole may run about in confusion and be unable to mount an effective response.

The same can be said about the caution factor. Companies with this factor have a strong tendency not to have a clear course of action in response to an emergency, but make decisions about their response on a case by case basis according to the situation.

\section{WHAT IS A STRONG ORGANIZATIONAL CULTURE IN AN EMERGENCY?}

During an emergency, things happen at a much faster speed than during normal times, and because concern is high among large numbers of people, feedback on response actions tends to be quite rapid. Those responding to emergencies are required to make quick broad-ranging decisions, and ensure those decisions are carried out. In this environment, there are major doubts about responses to emergencies through top-down tiered organizations with prepared response measures and manuals as suggested by conventional crisis management research.

In conventional crisis management research, a high level of dependence is placed on the capabilities of the top managers, and considering there are not a great number of supermen at the top of these companies, this is probably not practical. In this sense, we can say that companies with a strong suckerfish-type factor that are affected by the directions of the top management face a major risk in their response to emergencies.

In situations like an emergency in which timeliness is critical, it is desirable that leaders and workers at the workplace level who are closest to the situation as it unfolds work together and generate new policies and action plans to deal with the emergency.

Takada (2004) listed strengthening of the commitment of workers at the workplace as an element of a successful response to an emergency. Leaders at the workplace working together to share information and providing feedback on the result of actions taken is important for effecting a more coordinated response and raising motivation. Takada pointed out that if a company is structured to share and disseminate information within the organization using various media in addition to verbal communication; members of the organization will carry out actions in response to the emergency as a part 
of the motivation cycle, thereby heightening their commitment to the emergency response.

In this light, it can be surmised that companies with a cheerful family-type culture are better able to effect a coordinated response to an emergency. In the cheerful familytype culture, information tends to be passed on freely, and rather than having employees carry out response actions based on orders and directives conscious of the intentions of the top management, this culture prefers a commitment by the workplace in which employees carry out various response actions of their own free will.

This organizational culture factor also tends to prefer that members of the organization are connected through a warm human relationship, and are able to communicate openly where they are free to speak their mind. Under this culture, it is easier for companies to set up a structure in which broad-ranging information can circulate throughout the organization in an emergency, and this in turn will work to boost the commitment by workers and leaders at the workplace.

\section{CONCLUSION}

From this survey it is clear that the emergency response method that has been the standard for Japanese companies - the most important aspect for a coordinated response to an emergency is top-down leadership, and all information is concentrated at the top has accelerated the dissemination of information, and the response is actually being carried out at the workplace level.

In any response to an emergency, leadership by top management plays a significant role. However, this is not the "follow me" type of leadership indicated by previous crisis management research; rather, it serves the role as a billboard fulfilling the company's social responsibility by announcing its actions and thoughts outside the company. Top management must place greater importance on playing a positive role in ensuring accountability outside the company.

In the earliest stages of their response to an emergency, companies must set up and secure some form of communication system that can facilitate the circulation of information, considered to be the most important aspect of the response, and ensure that all members of the organization actively use this system. Prompt and thorough feedback by members of the organization during an emergency is also considered critical.

What must not be forgotten is that an emergency is not "a special situation separate from the normal state", but an "extension of the normal state". It is hard to perceive that 
the capability to respond to an emergency will suddenly rise simply because an emergency has occurred. It goes without saying that it is vital for companies to activate the circulation of information within the organization from the normal state, that is, they should foster a cheerful family-type organizational culture.

From here, I would like to conduct a detailed survey and analysis through interviews and the like regarding trends in the organizational culture obtained from this survey, and actual responses that companies have taken in an emergency.

Note: This survey was conducted with funding from the fiscal 2003 Musashi University Research Institute research subsidy (Research subsidy representative: Eri Yokota, Musashi University).

\section{REFERENCES}

Augustine,N (1995) "Managing the Crisis You Tried to Prevent," Harvard Business Review, November-December.

Bohn, Roger (2000 ) 'Stop fighting fires' . Harvard Business Review, July-August.

Inaba,M \& Fukagami,K (1989) "Soshiki to Kikikanri [Orgenization and Crisis Management ]" Soshiki Kagaku Jounral, Vol123.

Mitroff, I. \& Pearson, C. (1993). Crisis Management: A diagnostic guide for improving your organization's crisis-preparedness. Jossy-Bass Publishers.

Mitroff, Ian(1998) “Are You Prepared for a Crisis?” Innovative Leader Vol. 7, No. 8. August.

Myers, K.N. (1993). Total contingency planning for disasters: Managing risk, minimizing loss, ensuring business continuity. John Wiley \& Sons, Inc.

Oizumi, Koichi (1996). Kigyo no tame no saigai Kiki taio manual [Disaster emergency response manual for companies]. PHP Research Institute.

Sassa, A. (1979). Kiki taio no know-how: Shinrai sareru leader no joken [Emergency response know-how: Criteria for a reliable leader] PHP Research Institute.

Takada, A. (2004) "The Role of Team Efficacy in Crisis Management" International Journal of Emergency Management. Vo2 issue 1/2 p35-46. 